\title{
Diagnostic Potential of Polyclonal Antibodies Against Bacterially Expressed Recombinant Coat Protein of Alfalfa mosaic virus
}

\author{
B. Khatabi, B. He, and M. R. Hajimorad, Department of Entomology and Plant Pathology, The University of Tennessee, Knoxville
} 37996

\begin{abstract}
Khatabi, B., He, B., and Hajimorad, M. R. 2012. Diagnostic potential of polyclonal antibodies against bacterially expressed recombinant coat protein of Alfalfa mosaic virus. Plant Dis. 96:1352-1357.

Alfalfa mosaic virus (AMV), a pathogen of a wide range of plant species, including Glycine max (soybean), is poorly immunogenic. Polyclonal antibodies were generated against bacterially expressed recombinant coat proteins (rCPs) of two biologically distinct AMV strains in rabbits and compared with those raised against native and glutaraldehyde-treated virions of the same strains. Analyses showed that sera against rCPs had comparable antibody titers in indirect enzyme-linked immunosorbent assay with those raised against virions when soybean sap containing homologous viruses served as antigens. Polyclonal antibodies against $\mathrm{rCPs}$ were specific, sensitive, and de-

tected all AMV isolates that originated from soybean fields from geographically different regions of the United States. Comparison of CP genes of these isolates showed 96 to 99 and 96 to $100 \%$ nucleotide and amino acid sequence identities, respectively, suggesting that they are all closely related. This was further confirmed by phylogenetic analysis where they were all clustered together along with representative AMV strains belonging to group I. Collectively, our data demonstrate that, despite poor immunogenicity of AMV, polyclonal antibodies against $\mathrm{rCP}$ are effective probes for detection and diagnosis of the virus.
\end{abstract}

Alfalfa mosaic virus (AMV), the type species of the genus Alfamovirus within the family Bromoviridae, has a broad host range infecting more than 400 plant species in over 51 dicotyledonous families worldwide $(7,23)$. AMV exhibits considerable variability in pathogenicity, transmissibility, and symptom expression $(12,23)$. AMV is an emerging viral problem of soybean (Glycine $\max (\mathrm{L}$.) Merrill) in the United States, particularly in fields located in the Midwest $(6,9,19,27)$. In Wisconsin, AMV was found associated with yield reductions of 31 and 26\% in 2002 and 2003, respectively (27). In Nebraska, AMV was detected in 52 and 54\% of soybean fields surveyed during 2001 and 2002 growing seasons, respectively (9). AMV is transmitted by a large number of aphid species in a nonpersistent manner (23). However, the recent high incidence of AMV in soybean in these regions of the United States has been attributed to the introduction of the soybean-colonizing aphid (Aphis glycines) that is capable of transmitting the virus $(3,18,37)$. AMV is also transmitted in soybean via seed (15); however, the impact of seed transmission on its dispersal is unknown.

AMV infection in some soybean cultivars is symptomless (15). Occasionally, symptomatic soybean plants infected with AMV also exhibit a "recovery" phenomenon that is associated with the disappearance of the initially expressed symptoms combined with reduction in virus titers (16). These properties of AMV present challenges for its accurate detection in field-grown soybean based on symptomatology. Recently, sampling procedures for AMV detection in soybean were optimized (16).

Immunoassays, in particular various versions of enzyme-linked immunosorbent assay (ELISA), play crucial roles for detection and diagnosis of plant viruses, including AMV (21). In these assays, specific antibodies are the key component. Traditionally, plant

Corresponding author: M. R. Hajimorad, E-mail: mrh@utk.edu

Current address of B. He: College of Agriculture, Guangxi University, 100 Daxue Dong Road, Nanning, Guangxi, 530005, China.

Accepted for publication 9 April 2012.

http://dx.doi.org/10.1094/PDIS-08-11-0683-RE

(C) 2012 The American Phytopathological Society virologists have generated polyclonal antibodies against viral coat proteins (CPs) by utilizing purified virions as an immunogen (36). This procedure is lengthy, requiring virus propagation in a suitable host followed by virion purification $(21,36)$. To enhance immunogenicity of virions of some plant viruses, similar to AMV, which are intrinsically poorly immunogenic $(20,31,35)$, viral capsids are occasionally stabilized via treatment with glutaraldehyde or formaldehyde $(8,13,31)$. The positive impact of such a treatment on enhancement of immunogenicity of AMV has been reported (13).

In recent years, bacterial expression systems have been utilized for production of $\mathrm{CP}$ of plant viruses to be used as immunogens for generation of antibodies $(1,5,10,22)$. This approach, which has several advantages over conventional methods of immunogen preparation, bypasses virus propagation and purification (4). Protein expression and purification procedures, in most cases, are simple and easy to perform. Furthermore, the approach is fast, cost effective, and easy to scale up (4). Hence, expression of CP in bacteria is an alternative approach to classical methods for preparation of immunogen, particularly for viruses that, due to low concentration in their respective hosts, are difficult to purify $(4,32)$. However, a concern remains whether $\mathrm{CP}$ expressed in bacteria can serve as a potent immunogen for raising quality antisera suitable for diagnostic assays against poorly immunogenic plant viruses such as AMV.

In this study, we generated sera against bacterially expressed recombinant $\mathrm{CP}(\mathrm{rCP})$ of two biologically distinct strains of AMV and compared them for antibody titers, sensitivity, specificity, and diagnostic potential with those raised against native or glutaraldehyde-treated virions. Furthermore, we studied genetic variation and phylogenetic relationships of AMV isolates from soybean based on $\mathrm{CP}$ gene sequences.

\section{Materials and Methods}

Viruses and antisera. AMV isolates were collected from fieldgrown soybean in Illinois (isolates Joe Davis and Champaign, provided by L. L. Domier, University of Illinois at Urbana-Champaign), Indiana (SE12, provided by K. L. Perry, Cornell University), Kentucky (K1, provided by K. L. Perry), Tennessee (TN) (6), Virginia (S01-18, provided by S. A. Tolin, Virginia Tech), and Wisconsin (Ar15, C, Rotation, and SturdyII, provided by C. Grau, University of Wisconsin). AMV strains $\mathrm{W} 1$ and N20 were origi- 
nally isolated from lucerne (Medicago sativa) in South Australia (12) and obtained from the American Type Culture Collection (PV846 and PV849). Other soybean-infecting viruses that served as negative antigens in ELISA were Bean pod mottle virus (BPMV), Bean yellow mosaic virus (BYMV), Cucumber mosaic virus (CMV), Groundnut ringspot virus (GRSV), Peanut stunt virus (PSV), Soybean mosaic virus (SMV), Soybean vein necrosis-associated virus (SVNaV), Tobacco ringspot virus (TRSV), Tobacco streak virus (TSV), Tomato spotted wilt virus (TSWV), and Tomato yellow ring virus (TYRV). All these viruses, except GRSV, TSWV, and TYRV, which were parts of diagnostic kits supplied by AC Diagnostics Inc., originated from our virus collection.

Antisera to native and glutaraldehyde-treated virions of AMVN20 and AMV-W1 were reported earlier (13) and provided by J. W. Randles (Adelaide University, South Australia). The monoclonal antibody $(\mathrm{McAb})$ against polyhistidine was purchased from Sigma-Aldrich.

Mechanical inoculation and virus purification. Sap inoculum was prepared by grinding infected leaf tissues in the presence of $0.01 \mathrm{M}$ phosphate buffer, $\mathrm{pH} 7.0$ (12), and rub inoculated onto Carborundum-dusted (600-mesh) leaves of targeted plants. The inoculated plants were maintained in a growth chamber operating at $22^{\circ} \mathrm{C}$ with a photoperiod of $16 \mathrm{~h}$. AMV strains $\mathrm{N} 20$ and $\mathrm{W} 1$ were propagated in Nicotiana glutinosa and virions were purified according to Hajimorad and Francki (12). The purified virions in $0.01 \mathrm{M}$ phosphate buffer, $\mathrm{pH} 7.0$, were stored at $-20^{\circ} \mathrm{C}$ in the presence of $50 \%$ glycerol. AMV isolates from field-grown soybean were mechanically inoculated to primary leaves of 'Williams82'. The systemically infected trifoliate leaves were harvested at 28 days post inoculation, pulverized in the presence of liquid nitrogen, and stored at $-80^{\circ} \mathrm{C}$.

CP gene cloning. Total encapsidated viral RNAs were isolated from purified virions of AMV strains N20 and W1 as described previously (11). Primers utilized for reverse transcription (RT) and polymerase chain reaction (PCR) of the AMV CP gene for cloning purpose were designed based on published sequences of RNA3 from AMV strain 425M (GenBank accession number K02703). Viral RNAs extracted from purified virions were subjected to RT in the presence of primer a2043 (5'-AGGACTTCATACCTTGACC$3^{\prime}$ ) and SuperScript III reverse transcriptase (Invitrogen) according to the manufacturer's instructions. Subsequently, the generated RT products served as templates and the full-length CP gene was PCR amplified in the presence of Takara EX Taq polymerase (Takara Bio) and primers CP-f1 (5'-AGCTGAATTCATGAGTTCTTC ACAAAAG-3') and CP-r1 (5'-GCTAGCGGCCGCTCAATG ACGATCAAGATCG-3') (non-viral sequences are in bold and recognition sites for EcoRI and NotI in primers CP-f1 and CP-r1, respectively, are underlined). PCR reactions were done in a PTC200 DNA engine Thermal Cycler (Bio-Rad Laboratories). The PCR program consisted of a single cycle of 3 min at $95^{\circ} \mathrm{C} ; 32$ cycles of $20 \mathrm{~s}$ at $94^{\circ} \mathrm{C}, 30 \mathrm{~s}$ at $58^{\circ} \mathrm{C}$, and $1 \mathrm{~min}$ at $72^{\circ} \mathrm{C}$; followed by 1 cycle of $10 \mathrm{~min}$ at $72^{\circ} \mathrm{C}$. The resultant amplicons were cleaved with EcoRI and NotI restriction enzymes (New England BioLabs) and ligated into pET-28a (+) (Novagen) in frame with histidine hexamer tag (histidine-tag). The RT-PCR-amplified CP nucleotide sequences were sequenced to ensure absence of any PCR-generated error. Sequencing was performed at the University of Tennessee DNA Sequencing Facility (Knoxville).

CP expression, purification, and verification. The pET-28a (+)-containing $\mathrm{CP}$ gene was transferred into Escherichia coli $\left(\mathrm{DE}_{3}\right)$ $\mathrm{BL}_{21}$ (Stratagene). Bacteria were grown at $37^{\circ} \mathrm{C}$, and $\mathrm{CP}$ expression was induced following addition of $1 \mathrm{mM}$ isopropyl- $\beta$-D-thiogalctopyranoside (IPTG) (Promega Corp.) and further incubation for $3 \mathrm{~h}$. The recombinant poly-histidine-tagged expressed protein was purified using Ni-NTA affinity column chromatography under native conditions according to the instructions of the manufacturer (Qiagen). Recombinant protein was analyzed by sodium dodecyl sulfate (SDS)-discontinuous buffer polyacrylamide gel electrophoresis (PAGE) (25).
Production of antiserum against rCPs. Antisera were raised in two rabbits through a contract with Covance, Inc.. Each rabbit received a total of $875 \mu \mathrm{g}$ of histidine-tagged CP from strains N20 or W1 in six injections over a period of 181 days. Initially, $250 \mu \mathrm{g}$ of purified $\mathrm{rCP}$ emulsified with Freund's complete adjuvant $(1: 1$, $\mathrm{vol} / \mathrm{vol}$ ) was injected into each rabbit. Subsequently, five injections were administered, each with $125 \mu \mathrm{g}$ of $\mathrm{rCP}$ but in the presence of incomplete Freund's adjuvant at 3-week intervals. Blood was collected five times over the course of immunization at 10 days after each injection, starting from the second injection.

Serology. The antibody titers in the sera and their sensitivities and specificities were evaluated in antigen-coated indirect ELISA (AC-IELISA) (26). SDS-PAGE combined with western immunoblotting (34) were utilized for characterization of the expressed proteins from bacteria. To prepare antigen for AC-IELISA, pulverized soybean tissues stored at $-80^{\circ} \mathrm{C}$ were vortexed in the presence of carbonate buffer, $\mathrm{pH} 9.6$ (2), and centrifuged at 5,000 rpm for 2 $\min$ at $4{ }^{\circ} \mathrm{C}$. The clarified supernatant served as antigen for coating the wells. Phosphate-buffered saline (PBS) (2) containing $0.05 \%$ Tween 20 and 5\% nonfat dry milk, pH 7.4, served as the sample buffer. The anti-rabbit alkaline phosphatase conjugate (SigmaAldrich) was used at a dilution of 1:2000 in the sample buffer. The p-nitrophenyl phosphate (Sigma-Aldrich) in substrate buffer (2) was added and optical density (OD) values at $405 \mathrm{~nm}$ were recorded by a Microplate Reader Model 680 from Bio-Rad. OD values exceeding mean value of background (i.e., reaction with sap from noninoculated soybean) $+3 \times$ standard deviation were considered positive.

Sequence comparison and phylogenetic analysis. To obtain $\mathrm{CP}$ gene sequences, total RNA was extracted from infected soybean leaf tissues using the RNeasy Plant Mini Kit (Qiagen) and reverse transcribed in the presence of 10 -mer random primers. Primer pairs CP-f2 $5^{\prime}$-CCATCATGAGTTCTTCACAAAAG-3' and CP-r2 5'-TCAATGACGATCAAGATCGTC-3' (38) were utilized for PCR amplification. The resulting amplicons were purified using a QIAquick PCR purification kit (Qiagen) and directly sequenced. The sequences were homology searched using BLAST online programs (National Center for Biotechnology Information GenBank). Multiple sequence alignments were performed using Clustal X, version 2. The calculation of nucleotide identities and multiple sequence alignment editing were performed using GeneDoc, version 2.6.002 (28). A phylogenetic tree was constructed by MEGA software, version 4.0, based on the neighborjoining method and the interior reliability of each branch by the bootstrap method with 1,000 replicates (33). The CP gene sequences of AMV isolates from soybean generated in this study were deposited in GenBank under the following accession numbers: Ar-15 (JN256022), C (JN256024), Champaign (JN256019), K1 (JN256025), Rotation (JN256021), SE12 (JN256026), SturdyII (JN256023), and S01-18 (JN256020). Sequences of CP genes for other AMV strains utilized in this study were obtained from GenBank. These included Caa-1 (AJ130707), Da (Y09110), F-430 (AJ130706), Joe Davis (HQ185569), Lye-80 (AJ130703), N20 (HM807304), Tec-1 (FR715042), TN (HQ185568), W1 (HM807307), YSMV (M59241), 15/64 (AF015717), 126-A (AJ130704), 195-AN (AJ130705), 425L (L00162), and 425M (K02703).

\section{Results}

Cloning and expression of $\mathrm{CP}$ gene in bacteria. The fulllength CP gene of AMV strains N20 and W1, each with an expected size of 666 nucleotides encoding 221 amino acids, were RTPCR amplified and ligated into pET-28a (+) downstream of the histidine-tag. IPTG-induced $E$. coli containing the recombinant plasmid expressed a pronounced protein that ran as a single polypeptide band on Coomassie brilliant blue stained SDS-PAGE with an approximate molecular mass of $26 \mathrm{kDa}$ (data not shown). The recombinant nature of the expressed AMV-CP was verified by western immunoblotting using a McAb against histidine tag as well as polyclonal antibodies against AMV virions (data not shown). 
Evaluation of sera for antibody titers and specificity. Antisera against $\mathrm{rCP}$ of AMV strains $\mathrm{N} 20$ and $\mathrm{W} 1$ generated in this study, as well as the antisera raised earlier against native and glutaraldehyde-treated virions of the same strains (13), were recovered from the last bleedings of the immunized rabbits. Each antiserum was titrated by AC-IELISA against clarified sap from soybean plants infected with homologous viruses. In general, regardless of AMV strain serving as immunogen, sera raised against rCPs exhibited comparable antibody titers with those generated against native or glutaraldehyde-treated virions (Fig. 1A and B). The greatest dilutions of antisera against rCP, native, and glutaraldehyde-treated virions of AMV-N20 that reacted positively with sap from the infected tissues were 1:32,000 (OD $0.5 \pm 0.08), 1: 32,000$ (OD $0.6 \pm$ 0.04 ), and 1:128,000 (OD $0.5 \pm 0.03$ ), respectively. In regard to AMV-W1, all the sera had a slightly higher antibody titer compared with those raised against various antigenic conformations of AMV-N20 (Fig. 1; compare A with B). The greatest dilutions that antisera against $\mathrm{rCP}$, native, and glutaraldehyde-treated virions of AMV-W1, which reacted positively with sap from the AMV-W1infected tissues, were 1:64,000 (OD $0.6 \pm 0.02$ ), 1:64,000 (OD 0.5 $\pm 0.05)$, and 1:128,000 (OD $0.8 \pm 0.04)$, respectively.

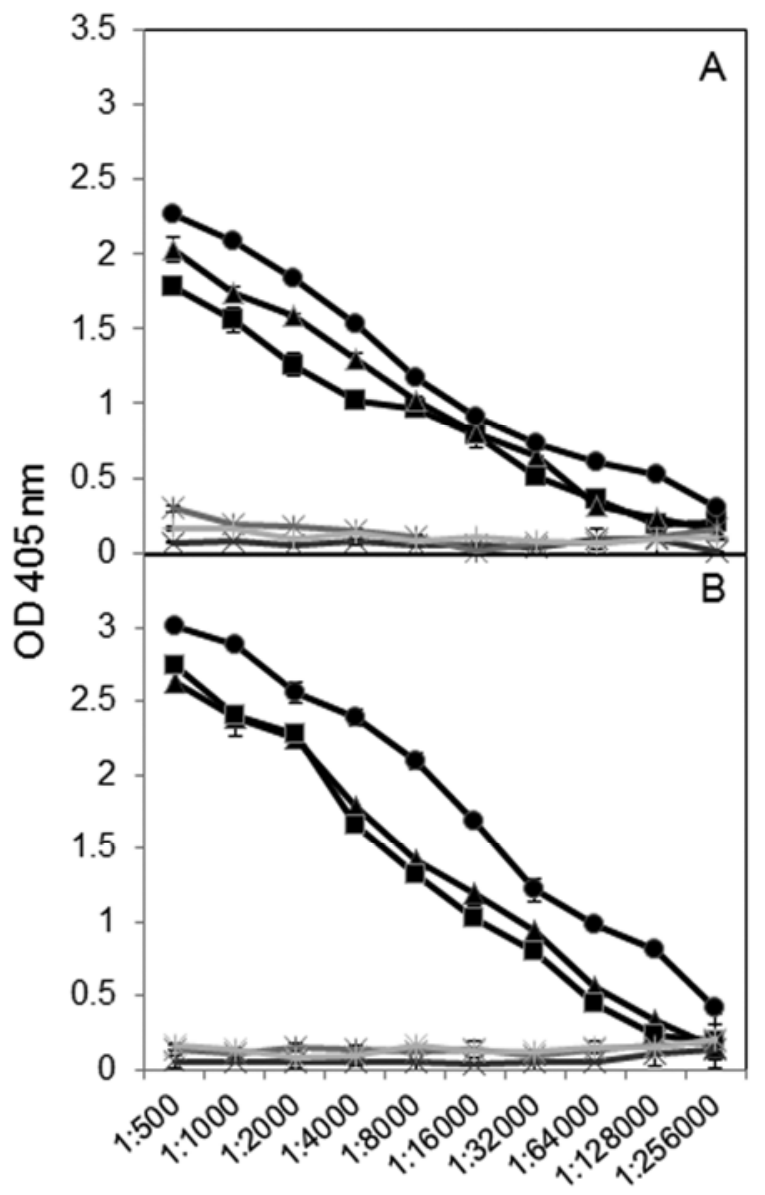

Antiserum dilution

Fig. 1. Comparison of antibody titers in sera raised in rabbits against recombinant coat protein $(\mathrm{rCP})(\mathbf{\square})$, native $(\boldsymbol{\Delta})$, and glutaraldehyde-treated $(\mathbf{\theta})$ virions of Alfalfa mosaic virus strains A, N20 and B, W1 by antigen-coated indirect enzymelinked immunosorbent assay. Plate wells were coated in triplicate with sap extracts in carbonate buffer, $\mathrm{pH} 9.6$ (1:20 wt/vol), from soybean leaf tissues infected with homologous viruses harvested at 28 days post inoculation. Serial dilutions of the antisera were prepared in phosphate-buffered saline containing $0.05 \%$ Tween 20 and $5 \%$ nonfat dry milk, $\mathrm{pH} 7.4$. Note the low level of cross-reactivity of serially diluted antisera generated against rCPs (+), native $(x)$, and glutaraldehyde-treated $\left.{ }^{*}\right)$ virions with sap extract from noninoculated soybean leaf tissues. Optical density (OD) values were recorded at $60 \mathrm{~min}$ after substrate hydrolysis. Bars indicate standard deviations.
All the antisera, regardless of the strain and the type of immunogen, showed high specificity toward AMV antigen. This was based on a low level of background of each of the antisera when tested against sap from noninoculated soybean leaf tissues (Fig. 1A and B). For antisera against rCP, native, and glutaraldehyde-treated virions of AMV-N20, the mean background OD values at $405 \mathrm{~nm}$ were $0.09 \pm 0.05,0.14 \pm 0.03$, and $0.13 \pm 0.04$, respectively. Similarly, for antisera generated against $\mathrm{rCP}$, native, and glutaraldehyde-treated virions of AMV-W1, the mean background OD values were $0.09 \pm 0.05,0.14 \pm 0.07$, and $0.18 \pm 0.07$, respectively. The antisera generated against rCP of AMV-N20 and AMV-W1 were also evaluated for their cross-reactivity against diverse virus species infecting soybean naturally (17). These included BPMV, BYMV, CMV, GRSV, PSV, SMV, SVNaV, TRSV, TSV, TSWV, and TYRV. The mean OD value for antiserum to $\mathrm{rCP}$ of AMV-N20 tested against all these viruses was $0.14 \pm 0.06$ while that of antiserum to $\mathrm{rCP}$ of AMV-W1 was $0.12 \pm 0.07$. Both OD values are comparable with those of background reactions of these antisera when tested against sap from noninoculated tissues.

Comparison of sensitivities of antisera. Sensitivities of antisera against rCPs were assessed by AC-IELISA and compared with the antisera to native and glutaraldehyde-treated virions of the

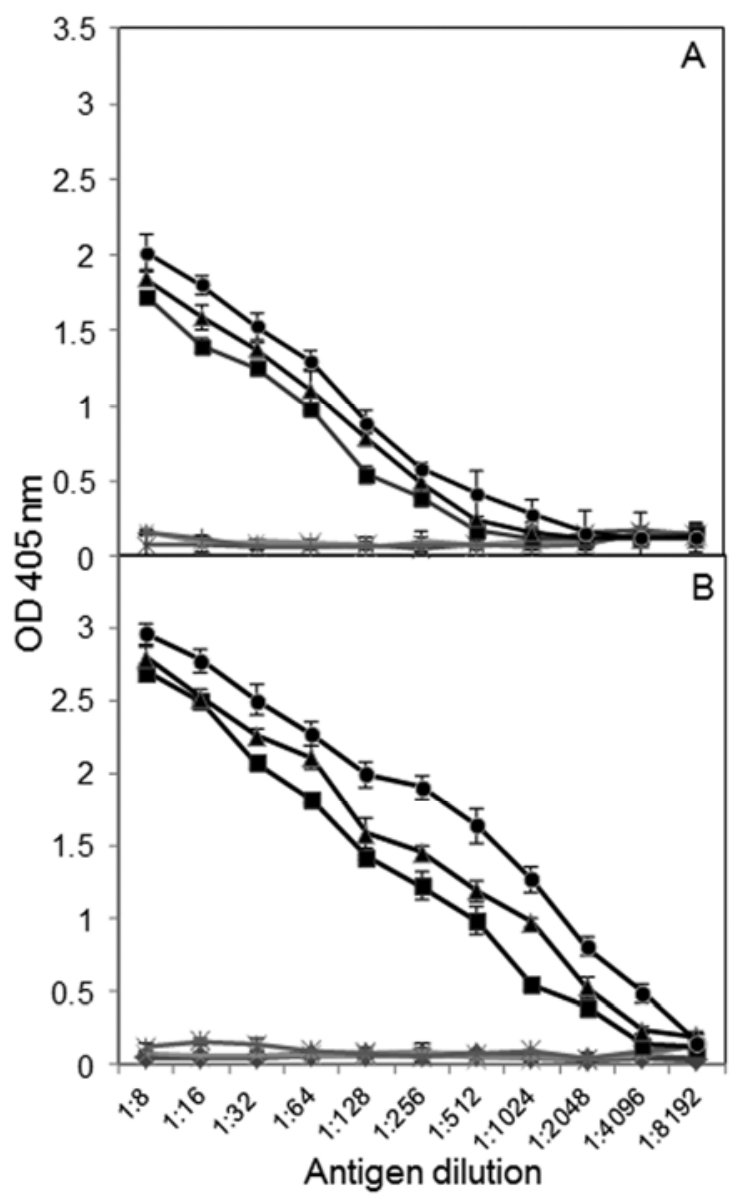

Fig. 2. Comparison of sensitivities of antisera raised in rabbits against recombinant coat protein $(\mathrm{rCP})(\boldsymbol{\square})$, native $(\mathbf{\Delta})$, and glutaraldehyde-treated $(\mathbf{O})$ virions of Alfalfa mosaic virus strains A, N20 and B, W1 to detect the lowest level of homologous viruses in diluted soybean sap by antigen-coated indirect enzymelinked immunosorbent assay. Plate wells were coated in triplicate with serial dilutions of sap extracts in carbonate buffer, $\mathrm{pH} 9.6$ (1:20 wt/vol), from soybean leaf tissues infected with homologous viruses harvested at 28 days post inoculation. Each antiserum with a constant dilution of 1:2000 in phosphate-buffered saline containing $0.05 \%$ Tween 20 and $5 \%$ nonfat dry milk, pH 7.4, was used as a probe. Note the low optical density (OD) values for antisera generated against rCP $(+)$, native (x), and glutaraldehyde-treated (*) virions with diluted sap extract from noninoculated soybean leaf tissues. OD values were recorded at $60 \mathrm{~min}$ after substrate hydrolysis. Bars indicate standard deviations. 
same strains (Fig. 2). The plate wells were coated with serial dilutions of sap extracts from soybean leaf tissues infected with AMVN20 or AMV-W1 (Fig. 2) and probed with a constant dilution (1:2000) of each of the antisera. Antisera against rCP, native, and glutaraldehyde-treated virions of AMV-N20 detected homologous AMV in sap up to dilutions 1:256 (OD $0.4 \pm 0.02$ ), 1:256 (OD 0.5 \pm 0.1 ), and 1:512 (OD $0.4 \pm 0.09$ ), respectively. Antisera against $\mathrm{rCP}$, native, and glutaraldehyde-treated virions of AMV-W1 were more sensitive and detected homologous antigen in sap extract at dilutions up to 1:1024 (OD $0.6 \pm 0.03$ ), 1:2048 (OD $0.5 \pm 0.08$ ), and 1:4096 (OD $0.5 \pm 0.08$ ), respectively. Thus, sensitivity of antiserum to glutaraldehyde-treated virions of AMV-N20 was twice as high as the antisera raised against $\mathrm{rCP}$ and native virions of the virus. On the other hand, antiserum to native virions of AMV-W1 was twice as sensitive as to the one raised against $\mathrm{rCP}$ whereas antiserum against glutaraldehyde-treated virions was four and two times more sensitive compared with those to rCP and native virions, respectively. Thus, antisera to glutaraldehyde-treated virions of both strains showed slightly higher sensitivities compared with those raised against $\mathrm{rCP}$ or native virions.

Detection of AMV isolates from soybean that originated from geographically different regions with antisera against rCPs. Abilities of antisera against rCPs to detect various isolates of AMV from soybean was evaluated by AC-IELISA. Ten isolates of AMV from soybean fields in Illinois, Indiana, Kentucky, Tennessee, Virginia, and Wisconsin were mechanically transmitted to Williams82. When sap extracts from the infected leaf tissues were probed with the antisera against rCP of AMV-N20 or AMV-W1, all were detected efficiently (Fig. 3). Nevertheless, the OD values for antiserum to AMV-W1 rCP were higher than those obtained when probed with antiserum to AMV-N20 rCP (Fig. 3). This is likely a reflection of differences in antibody titers between the two sera (Fig. 1).

Genetic variation and phylogenetic relationships among $\mathbf{C P}$ gene of AMV isolates from soybean. Cross-reactivity of antisera generated against rCPs with all AMV isolates from field-grown soybean as well as lack of any genetic information on AMV isolates naturally infecting soybean prompted us to investigate their sequence diversity based on $\mathrm{CP}$ gene sequences. $\mathrm{CP}$ gene sequences from soybean AMV isolates shared 96 to $99 \%$ and 96 to $100 \%$ nucleotide and amino acid sequence identities, respectively (data not shown). When CP sequences of these isolates were compared with those of AMV-N20, AMV-W1, and selected strains

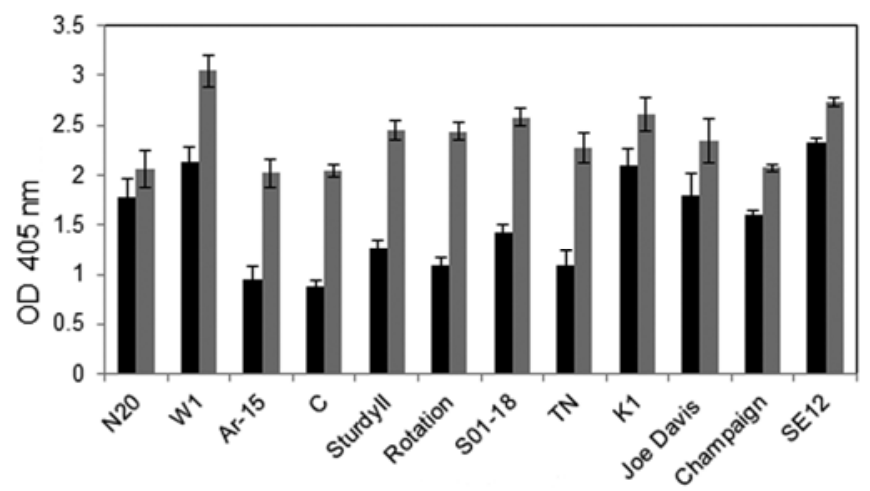

Fig. 3. Abilities of antisera raised against recombinant coat protein of Alfalfa mosaic virus (AMV) strains N20 (black bars) and W1 (gray bars) to detect homologous viruses and AMV isolates collected from soybean fields grown in various geographical regions of the United States by antigen-coated indirect enzyme-linked immunosorbent assay. AMV isolates Ar-15, C, Rotation, and Sturdyll were collected in Wisconsin; S01-18 in Virginia; TN in Tennessee; K1 in Kentucky; Joe Davis and Champaign in Illinois; and SE12 in Indiana. A dilution of 1:2000 (vol/vol) of each antiserum was utilized as a probe. Soybean sap extracts from systemically infected 'Williams82' leaf tissues harvested at 28 days post inoculation in carbonate buffer, pH 9.6 (1:20 wt/vol), served as antigen. Optical density (OD) values shown were recorded at $60 \mathrm{~min}$ after substrate hydrolysis and represent the net values after deducting the corresponding backgrounds. Each of the OD values represents mean value for four replicate plants. Bars indicate standard deviations. representing phylogenetically distinct groups of AMV (29,30,38; see Figure 4 for names of strains), they shared 93 to 99 and 92 to $100 \%$ sequence identity at nucleotide and amino acid levels, respectively (data not shown). Analysis of the nucleotide sequences of $\mathrm{CP}$ genes showed that all soybean isolates belonged to AMV phylogenetic group I and occupied the same clade in the tree (Fig 4). AMV strains N20 and W1, originally isolated from lucerne in South Australia, also clustered in this group (Fig. 4). As anticipated, strains Da, 126-A, 195-AN, F-430, 425L, 425M, and YSMV clustered in group I, while strains Caa-1, Lye-80, and 15/64 formed group IIA and Tec-1 was in group IIB $(29,30)$.

\section{Discussion}

To produce antibodies against viruses, plant virologists conventionally have propagated the virus of interest in a suitable host, purified virions, and utilized them as immunogens. This is a lengthy and time-consuming approach requiring ample greenhouse space for plant propagation and various centrifuges for virus purification, as well as skilled personnel. Additionally, not all plant viruses are easily transmissible in the laboratory and there is no universal purification method applicable to all strains of a particular virus. Some viruses present additional challenges. For example, phloem-limited viruses, such as luteoviruses, are present at very low concentrations in their hosts, resulting in low yield of purified virions (21).

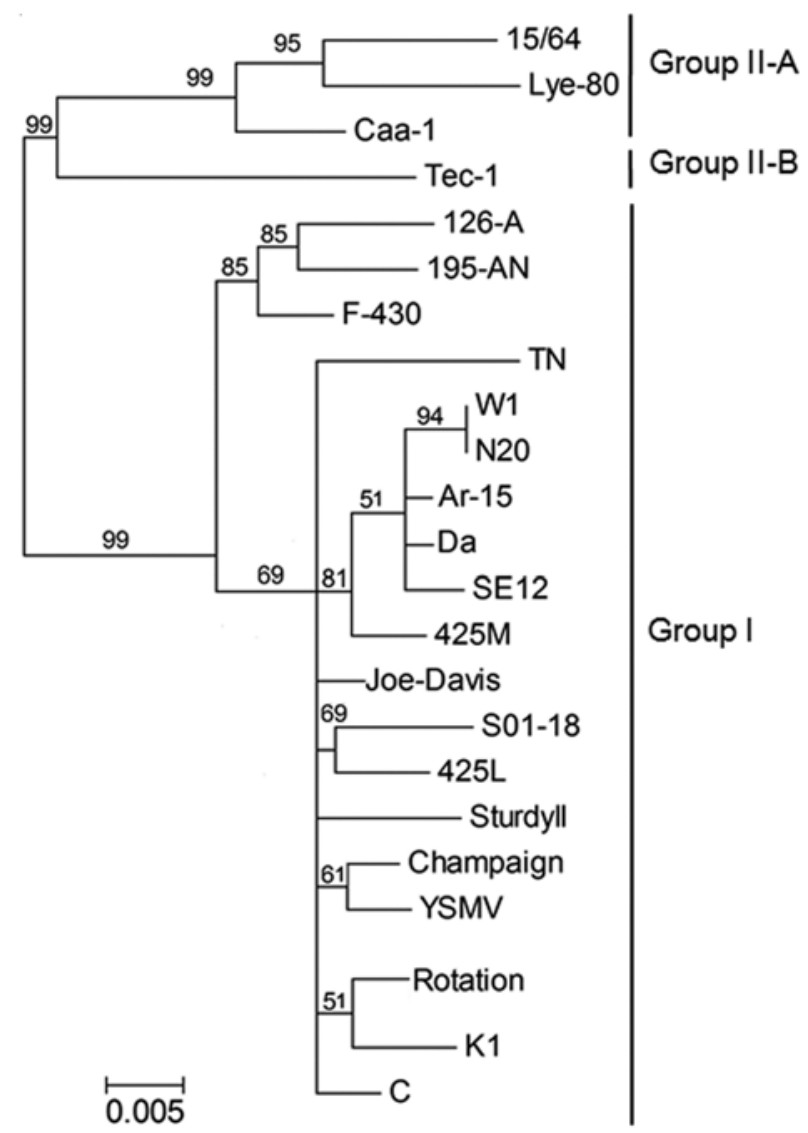

Fig. 4. Phylogenetic tree of coat protein (CP) gene sequences of Alfalfa mosaic virus (AMV) isolates from soybean, AMV-N20 and AMV-W1 from lucerne, and representative strains from established phylogenetic grouping of AMV. Sequences of isolates Ar-15, C, Champaign, K1, Rotation, SE12, Sturdyll, and S01-18 were generated in this study and deposited as GenBank accession numbers JN256022, JN256024, JN256019, JN256025, JN256021, JN256026, JN256023, and JN256020, respectively. Other AMV CP gene sequences were obtained from GenBank under the following accession numbers: Caa-1 (AJ130707), Da (Y09110), F-430 (AJ130706), Joe Davis (HQ185569), Lye-80 (AJ130703), N20 (HM807304), Tec-1 (FR715042), TN (HQ185568), W1 (HM807307), YSMV (M59241), 15/64 (AF015717), 126-A (AJ130704), 195-AN (AJ130705), 425L (L00162), and 425M (K02703). Note that all AMV isolates from soybean were placed in group I. Phylogenetic analysis was done with MEGA 4. Bootstrap values are indicated at branches. 
An alternative approach is to produce structural proteins of viruses, in particular $\mathrm{CP}$, in bacteria and use them as immunogens. However, proteins produced in this manner are mostly in denatured forms; hence, their conformations differ from those present on assembled virions. Thus, the likelihood that the generated serum against $\mathrm{rCP}$ would be low in antibody titer or fail to recognize intact virion is a matter for concern. There are three types of epitopes (i.e., antigenic sites) associated with viral particles and viral subunits (24). Intact viral particles possess unique epitopes known as neotopes. These types of epitopes owe their existence to conformational changes of $\mathrm{CP}$ induced by intersubunit bonds or may arise from juxtaposing residues from neighboring subunits on assembled virions $(24,36)$. On the other hand, CP subunits possess two different conformational epitopes. One group is present only on the surface of $\mathrm{CP}$ subunits, known as cryptotopes, but turn inward and become buried after virion assembly $(24,36)$. Thus, antibodies directed against cryptotopes do not recognize virions or aggregated forms of subunits. However, CP subunits also possess epitopes that are common to both intact virions as well as dissociated CP subunits and are known as metatopes $(24,36)$. Antibodies directed against metatopes recognize the intact virions, which are present in an infected plant. Thus, one assumes that sera generated in response to immunization to expressed $\mathrm{CP}$ gene in bacteria to be generally low in antibody titer suitable for diagnostics, unless the proteins targeted for detection are in denatured forms, such as in western immunoblotting.

In this study, we generated antibodies suitable for diagnostics via immunization of rabbits with $\mathrm{rCP}$ of AMV, an unstable and poorly immunogenic virus $(13,20,31,35)$. Our data clearly demonstrate that sera to rCPs of two biologically distinct strains of the virus had antibody titers comparable with those raised to native or glutaraldehyde-treated virions. Furthermore, they show that antisera to rCPs are sensitive and highly specific and are effective probes to detect geographically diverse isolates of AMV from soybean in AC-IELISA. Recently, it was also shown that antiserum generated against rCP of Pelargonium zonate spot virus, another member of the Bromoviridae family with unstable and poor immunogenic virions, was effective for detection and diagnosis of the virus when a denatured form of viral antigen was tested (10).

We used AC-IELISA, a variant of IELISA, for evaluation of the antisera. IELISA is highly sensitive and, unlike double-antibody sandwich ELISA (DAS-ELISA), does not require purified immunoglobulin (36). Furthermore, it does not require preparation of enzyme-linked conjugated antibody for every particular antibody at hand, because such conjugates can be purchased commercially (31). In our study, AC-IELISA offered additional advantages. AMV particles are unstable and are prone to degradation at high $\mathrm{pH}$ when incubated in carbonate buffer, $\mathrm{pH}$ 9.6; hence, the antigenic conformations that are presented to the probing antibodies are more likely in the form of degraded particles (14). Moreover, under this condition, AMV antigen adsorbs efficiently to the plate wells (14). As such, combination of these factors has a positive impact on the effectiveness of the antibodies to $\mathrm{rCP}$ for detection of AMV in sap extracts from infected plants. However, it is possible that antibodies to $\mathrm{rCP}$ would not be as effective in DAS-ELISA as in AC-IELISA. This is mainly due to differences in viral antigenic conformations presented to the probing antibodies in these two assays. The experimental conditions of DAS-ELISA, unlike AC-IELISA, are more suitable for preserving the integrity of virions (36).

Analyses of $\mathrm{CP}$ gene sequences of AMV isolates from soybean showed a high level of sequence identity in line with close serological relationships among them. AMV isolates from soybean also shared high levels of nucleotide and amino acid sequence identity when compared with strains representing phylogenetically distinct groups of the virus $(29,30,38)$. Previous studies of AMV isolates from lucerne and potato (Solanum tuberosum) that originated in Australia and Canada, respectively, also demonstrated close serological and genetic relationships $(12,38)$. These observations suggest that $\mathrm{CP}$ of AMV is highly conserved, possibly due to multiple crucial functions that it plays in the life cycle of the virus (23). Regardless, due to the presence of high levels of CP sequence identities among AMV strains, it is likely that polyclonal antibodies generated to rCPs of strains N20 and W1 will cross-react with a wide range of AMV isolates infecting other plant species.

AMV strains from other hosts and regions of the world have been clustered into two distinct phylogenetic groups based on $\mathrm{CP}$ gene sequences $(29,30,38)$. Phylogenetic analysis of AMV isolates from soybean along with strains representative of these phylogenetic groups showed that all the isolates from soybean belonged to group I. Interestingly, AMV strains N20 and W1 isolated in South Australia from lucerne also grouped with the isolates from soybean. North American strains 425L and 425M from clover and YSMV from lucerne as well as tomato-infecting strains Da and 195-AN from Italy also clustered with AMV isolates from soybean (Fig. 4). Thus, phylogenetic groupings of AMV strains did not provide a clear distinction among AMV isolates in regard to the geographical or host of origin. As suggested by Parrella et al. (30), it is highly likely that the genetic determinants of AMV for host specificity do not reside on $\mathrm{CP}$ gene but are located elsewhere in the genome.

\section{Acknowledgments}

This work was supported, in part, by a grant from North Central Soybean Research Program and Tennessee Soybean Promotion Board. We thank C. Grau (University of Wisconsin), L. L. Domier (University of Illinois at Urbana-Champaign), K. L. Perry (Cornell University), and S. A. Tolin (Virginia Tech) for providing AMV isolates from soybean; and J. W. Randles (Adelaide University, Australia) for antisera to AMV virions.

\section{Literature Cited}

1. Abou-Jawdah, Y., Sobh, H., Cordahi, N., Kawtharani, H., Nemer, G., Maxwell, D. P., and Nakhla, M. K. 2004. Immunodiagnosis of prune dwarf virus using antiserum produced to its recombinant coat protein. J. Virol. Methods 121:31-38.

2. Clark, M. F., and Adams, A. N. 1977. Characteristics of the microplate method of enzyme-linked immunosorbent assay for the detection of plant viruses. J. Gen. Virol. 34:475-483.

3. Clark, A. J., and Perry, K. L. 2002. Transmissibility of field isolates of soybean viruses by Aphis glycines. Plant Dis. 86:1219-1222.

4. Demain, A. L., and Vaishnav, P. 2009. Production of recombinant proteins by microbes and higher organisms. Biotechnol. Adv. 27:297-306.

5. Durrin, J. S., Nikolaeva, O. V., Strausbaugh, C. A., and Karasev, A. V. 2010 Immunodetection of two curtoviruses infecting sugar beet. Plant Dis. 94:972-976.

6. Fajolu, O. L., Wen, R.-H., and Hajimorad, M. R. 2010. Occurrence of Alfalfa mosaic virus in soybean in Tennessee. Plant Dis. 94:1505.

7. Fauquet, C. M., Mayo, M. A., Maniloff, J., Desselberger, U., and Ball, L. A. 2005. Virus Taxonomy, Classification and Nomenclature of Viruses: Eighth Report of the International Committee on the Taxonomy of Viruses. Academic Press.

8. Francki, R. I. B., and Habili, N. 1972. Stabilization of capsid structure and enhancement of immunogenicity of cucumber mosaic virus ( $Q$ strain) by formaldehyde. Virology 48:309-315.

9. Giesler, L. J., and Ziems, A. D. 2006. Incidence of Alfalfa mosaic virus, Bean pod mottle virus and Soybean mosaic virus in Nebraska soybean fields. Plant Health Progress. Online publication. doi:10-1094/PHP-20060424-01-HM

10. Gulati-Sakhuja, A., Sears, J. L., Nunez, A., and Liu, H.-Y. 2009. Production of polyclonal antibodies against Pelargonium zonate spot virus coat protein expressed in Escherichia coli and application for immunodiagnosis. J. Virol. Methods 160:29-37.

11. Hajimorad, M. R., Eggenberger, A. L., and Hill, J. H. 2003. Evolution of Soybean mosaic virus-G7 molecularly cloned genome in Rsv1-genotype soybean results in emergence of a mutant capable of evading $R s v 1$-mediated recognition. Virology 314:497-509.

12. Hajimorad, M. R., and Francki, R. I. B. 1988. Alfalfa mosaic virus isolates from lucerne in South Australia: biological variability and antigenic similarity. Ann. Appl. Biol. 113:45-54.

13. Hajimorad, M. R., and Francki, R. I. B. 1991. Effect of glutaraldehydefixation on the immunogenicity, particle stability and antigenic reactivity of alfalfa mosaic virus, and the specificity of elicited antibodies. J. Virol. Methods 33:13-25.

14. Hajimorad, M. R., and Francki, R. I. B. 1991. Some observations on the binding properties of alfalfa mosaic virus to polystyrene and its significance to indirect ELISA. Arch. Virol. 117:219-235.

15. He, B., Fajolu, O. L., Wen, R.-H., and Hajimorad, M. R. 2010. Seed transmissibility of Alfalfa mosaic virus in soybean, Plant Health Progress. Online publication. 10.1094/PHP-2010-1227-01-BR 
16. He, B., Hill, J. H., and Hajimorad, M. R. 2011. Factors to improve detection of Alfalfa mosaic virus in soybean. Plant Health Progress. Online publication. 10.1094/PHP-2010-0926-02-RS

17. Hill, J. H. 1999. Soybean mosaic. Pages 70-71 in: Compendium of Soybean Diseases. G. L. Hartman, J. B. Sinclair, and J. C. Rupe, eds. American Phytopathological Society, St. Paul, MN.

18. Hill, J. H., Alleman, R., Hogg, D. E., and Grau, C. R. 2001. First report of transmission of Soybean mosaic virus and Alfalfa mosaic virus by Aphis glycines in the New World. Plant Dis. 85:561.

19. Hobbs, H. A., Herman, T. K., Slaminko, T. L., Wang, Y., Nguyen, B. T., McCoppin, N. K., Domier, L. L., and Hartman, G. L. 2010. Occurrence of soybean viruses, fungal diseases, and pests in Illinois soybean rust sentinel plots. Plant Health Progress. Online publication. doi:10-1094/PHP-20100827-01-BR

20. Hull, R. 1969. Alfalfa mosaic virus. Adv. Virus Res. 15:365-433.

21. Hull, R. 2002. Matthews' Plant Virology. Academic Press, New York

22. Iracheta-Cárdenas, M., Sandoval-Alejos, B. D., Román-Calderón, M. E., Manjunath, K. L., Lee, R. F., and Rocha-Peña, M. A. 2008. Production of polyclonal antibodies to the recombinant coat protein of Citrus tristeza virus and their effectiveness for virus detection. J. Phytopathol. 156:243-250.

23. Jaspars, E. M. J., and Bos, L. 1980. Alfalfa mosaic virus. Commonw. Mycol. Inst./Assoc. Appl. Biol. Descr. Plant Viruses No. 229.

24. Jerne, N. K. 1960. Immunological speculations. Annu. Rev. Microbiol. 14:341-358.

25. Laemmli, U. K. 1970. Cleavage of structural proteins during the assembly of the head of bacteriophage T4. Nature 227:680-685.

26. Malapi-Nelson, M., Wen, R.-H., Ownley, B. H., and Hajimorad, M. R. 2009. Co-infection of soybean with Soybean mosaic virus and Alfalfa mosaic virus results in disease synergism and alteration in accumulation level of both viruses. Plant Dis. 93:1259-1264.

27. Mueller, E. E., and Grau, C. R. 2007. Seasonal progression, symptom development, and yield effects of Alfalfa mosaic virus epidemics on soy- bean in Wisconsin. Plant Dis. 91:266-272.

28. Nicholas, K. B., Nicholas, H. B., Jr., and Deerfield, D. W. II. 1997. GeneDoc: analysis and visualization of genetic variation. EMBNew. News 4:14.

29. Parrella, G., Acanfora, N., Orílio, A. F., and Navas-Castillo, J. 2011. Complete nucleotide sequence of a Spanish isolate of alfalfa mosaic virus: Evidence for additional genetic variability. Arch. Virol. 156:1049-1052.

30. Parrella, G., Lanave, C., Marchoux, G., Finetti Sialer, M. M., Di Franco, A., and Gallitelli, D. 2000. Evidence for two distinct subgroups of Alfalfa mosaic virus (AMV) from France and Italy and their relationships with other AMV strains. Arch. Virol. 145:2659-2667.

31. Rybicki, E. P., and Von Wechmar, M. B. 1985. Serology and Immunochemistry. Pages 207-244 in: The Plant Viruses, Vol. 1. R. I. B. Francki, ed. Plenum Press, New York.

32. Shams-bakhsh, M., and Symons, R. H. 2004. Cloning and expression of the coat protein gene of Barley yellow dwarf virus-PAV in Escherichia coli. Iran. J. Biotechnol. 2:84-89.

33. Tamura, K., Dudley, J., Nei, M., and Kumar, S. 2007. MEGA4: molecular evolutionary genetics analysis (MEGA) software version 4.0. Mol. Biol. Evol. 24:1596-1599.

34. Towbin, H., Staehelin, T., and Gordon, J. 1979. Electrophoretic transfer of proteins from polyacrylamide gels to nitrocellulose sheets: procedure and some applications. Proc. Natl. Acad. Sci. USA 76:4350-4354.

35. Tremaine, J. H and Chidlow, J. W. 1974. Partial separation on DEAEsephadex of antibodies reactive with plant viruses and their protein subunits. J. Gen. Virol. 24:229-236.

36. Van Regenmortel, M. H. V. 1982. Serology and Immunochemistry of Plant Viruses. Academic Press Inc., New York.

37. Wang, R. Y., and Ghabrial, S. A. 2002. Effect of aphid behavior on efficiency of transmission of Soybean mosaic virus by the soybean-colonizing aphid, Aphis glycines. Plant Dis. 86:1260-1264.

38. $\mathrm{Xu}, \mathrm{H}$., and Nie, J. 2006. Identification, characterization, and molecular detection of Alfalfa mosaic virus in potato. Phytopathology 96:1237-1242. 